\title{
UDC
}

\author{
I. N. Ilienko $\bowtie$, D. A. Bazyka
}

State Institution «National Research Center for Radiation Medicine of the National Academy of Medical Sciences of Ukraine», Melnykov str., 53, Kyiv, 04050, Ukraine

\section{Overexpression of TP53, TP53I3 and BIRC5, alterations of gene regulation of apoptosis and aging of human immune cells in a remote period after radiation exposure}

Objective. To identify a contributive role of changes in gene regulation of apoptosis and telomere length at transcriptional and translational levels to the formation of radiation-induced effects in immune system.

Patients and Methods. Study groups included 310 Chornobyl (Chornobyl) cleanup workers (dose of external exposure $(360.82 \pm 32.3) \mathrm{mSv}$; age $58.9 \pm 0.6(M \pm S D)$ years $)$ and control $(n=77 ;$ age $(52.9 \pm 0.64)(M \pm S D)$ years $)$. Expression of $\mathrm{CD} 95$, phosphatidylserine receptors, bcl2 and $\mathrm{p} 53$ proteins was studied by flow cytometry; the relative expression (RQ) of BAX, BIRC5, FASLG, MADD, MAPK14, TP53, TP53/3, TERT, TERF1, TERF2 genes was performed using 7900 HT Fast RT-PCR System and TagMan technology. Relative telomere length (RTL) was quantified by flow-FISH assay.

Results. Dose-dependent deregulation of apoptosis was shown at transcriptional level (TP53, TP53 I3, BAX, BIRC5, FASL genes) and translational level (bcl-2 and p53 proteins) with blocking entry to apoptosis, dose-dependent activation of anti-apoptotic proteins and TP53-mediated expression of genes-inhibitors of apoptosis. After exposure below 100 $\mathrm{mSv}$ a decrease in TERT gene RQ was associated with shortened telomeres, after exposure to doses over $500 \mathrm{mSv}$ the TERT RQ and RTL increase were associated with imbalance in TERF1 and TERF2 genes expression.

Conclusion. Our study demonstrates a presence of subsequent changes in gene expression, regulatory proteins presentation, telomere length and distribution of cells by the stages of apoptosis in a late period after radiation exposure from low-dose range to doses over $500 \mathrm{mSv}$. Results of the study contribute to the basic concepts on the late biological effects in immune system.

Key words: gene expression, apoptosis, telomeres, radiation, Chornobyl.

Problems of radiation medicine and radiobiology. 2016;21:238-246.

Ільєнко Ірина Миколаївна, e-mail: ilyenko@ukr.net 


\section{INTRODUCTION}

The development of long-term effects of ionizing radiation (IR) is the trigger point for scientific development and research of radiation medicine, radiobiology and clinical performance is confirmed by monitoring the health of contingent affected by the Chornobyl accident [1]. Research conducted over the period after the disaster show that a significant increase in somatic and oncologic pathology is a consequence of radiation induced destabilization of the human genome [2, 3]. Search for unique and permanent «signature» in the human genome, which has been left by ionizing radiation, reveals changes in gene expression after chronic radiation exposure [4], which are associated with the increased risks of chronic non-neoplastic diseases [5] and cancer [6]. It is questioned whether the involved genes complexes are unique or may be different, depending on a radiation dose. However, gene expression findings are mainly generated by the experimental studies. In «Mayak» plant workers 40-50 years after start of exposure the gene sets were revealed that are associated with plutonium incorporation (HNRNPA1, RAPGEF1 and SERPINB9) as well as with atherosclerosis. Connection with gamma radiation dose wasn't significant [7]. Thus, the role of gene expression changes in humans and relation to radiation dose at the remote period remains unclear. Therefore, it is necessary to study the impact of modifying ion on systemic violations of apoptosis gene regulation at the transcriptional and translational levels in remote post-radiation period. It is shown that enhancers and inhibitors of apoptosis or directly affecting on cell death mechanisms, or indirectly - by influencing of transcription regulation [12].

The presence of radiation aging in radiation-exposed at the Chornobyl accident is the most controversial aspect of the biological effects of ionizing radiation. Accelerated aging was demonstrated in clean-up workers, basing on hematopoietic and cardiovascular system indices. Shortening of telomeric sequences in peripheral blood (PB) leukocytes was demonstrated in cleanup workers in the remote period after exposure. According to other studies these changes cannot be considered definitively proven [14].

Therefore, it is necessary to study modifying effects of ionizing radiation on the regulation of apoptosis and aging at transcriptional and translational levels and their connection to in remote post-radiation period.

\section{PATIENTS AND METHODS}

Study groups included 310 Chornobyl cleanup workers (male) with average external dose exposure of (360.82 \pm 32.3) $\mathrm{mSv}(\mathrm{M} \pm \mathrm{SD})$ (mean age 58.9 \pm 0.6 ) and control group of 77 non-exposed male individuals (mean age $52.9 \pm 0.64)$. The main group of Chornobyl cleanup workers was divided into 3 subgroups: I subgroup includes liquidators of the Chornobyl remote period irradiated at doses below $100 \mathrm{mSv}$, the II group consisted of cleanup workers with external exposure dose in a range of 100 to $500 \mathrm{mSv}$ and III subgroup - clean-up workers exposed to doses of $500 \mathrm{mSv}$ and more.

\section{Telomere analysis by fluorescence \\ in situ hybridization and flow cytometry}

The relative telomere length (RTL) was studied using the Telomere PNA Kit / FITC (DakoCytomation, Denmark) for hematopoietic cells using PNA probe labeled with FITC. FISH stage included preprocessing, denaturation, hybridization (the 1st day), washing, DNA staining, and analysis (the 2nd day). K562 cell line with long and determined telomere length was used as control cells. Hybridized samples with FITClabelled PNA were counted at FACSCalibur cytometer.

RTL was calculated by the equation as a follows (1.1):

$$
\begin{aligned}
& \text { (mean FL1 sample cells with probe PNA) - } \\
& \text { (mean FL1 sample cells without probe PNA) }
\end{aligned}
$$

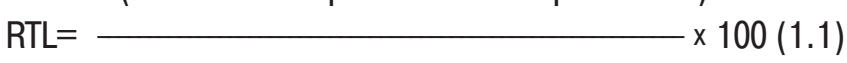

$$
\begin{aligned}
& \text { (mean FL1control cells with probe PNA) - } \\
& \text { (mean FL1 controlcells without probe PNA) }
\end{aligned}
$$

\section{Real-time polymerase chain reaction} (relative quantification of gene expression)

The relative expression of $B A X, B I R C 5, F A S L G$, MADD, MAPK14, MKNK2, TERF1, TERF2, TERT, TP53, TP53I3 genes was performed by a polymerase chain reaction with real-time reverse transcription (RT-PCR). RNA was purificated from PB mononuclear using the automated QIAcube workstation (QIAGENE, Germany) with a spin-column NucleoSpin RNAII (Macherey-Nagel, Germany kit for RNA purification) and DNAse processing. cDNA was synthesized from purificated RNA samples with the High Capacity cDNA Reverse Transcription Kit (Applied Biosystems, USA). Amplification of cDNA was performed using 7900 HT Fast RT-PCR System with TagMan Low Density Array Plate (Applied Biosystems, USA). Data was analyzed and the relative levels of gene expression (RQ) were calculated using the SDS 2.3 and RQManager software. 


\section{Flow cytometry study}

Expression of CD95, bcl2, p53 proteins and molecule of phosphatidylserine investigated by flow cytometry using monoclonal antibodies: CD95 FITC Mouse AntiHuman, Bcl-2 PE Mouse Anti-Human, FITC Mouse Anti-p53 Antibody Set and FITC Annexin-V Apoptosis Detection Kit I (BD, USA) by standard protocol for surface and intra stain flow cytometry technology. Analysis was performed on laser flow cytometers FACScan and FACSCalibur (BD, USA).

\section{RESULTS AND DISCUSSION}

\section{Dysregulation of apoptosis at transcriptional and translational levels in the remote period after exposure}

The signal for the start of apoptosis is the interaction of specific extracellular ligands with cell death receptors that are expressed on the surface of the cell membrane. At the stage of ligand, receptor binding can be characterized readiness cells to apoptosis. We investigated the spontaneous expression of CD95 antigen in groups of cleanup workers (Table 1). A significant increase in expression of FAS-receptor in dose subgroups of clean-up workers compared with controls was demonstrated. The average level of expression of CD95 antigen increased with dose. The highest value was recorded in the group of exposed at doses over $500 \mathrm{mSv}$. Analysis of intracellular expression of anti-apoptotic protein Bcl-2 in PB lymphocytes of cleanup workers showed a reduced expression of this marker in all dose subgroups to the control with absence of statistic differences between the dose subgroups. Obtained data demonstrate an increase of cells preparedness to initiate an altruistic death process alongside with a reduced expression of antiapoptotic proteins. Different strength of correla- tions between the bcl-2 protein expression and radiation dose was revealed in dose subgroups: subgroup I $-r=0.39$, subgroup II $-r=0.17$, subgroup III $-r=$ $0.23(\mathrm{p}<0.05)$.

The quantification of cells number entering the advanced stages of apoptosis demonstrated a decrease of cells in the early stages of apoptosis with Annexin+PI- phenotype in the most exposed third subgroup of cleanup workers compared to the control. In subgroups I and II an increase of apoptotic cell number was shown. The average numbers of cells at the advanced stages of apoptosis by dose subgroups were not changed. None of significant changes were found in the percentage of necrotic Annexin-PI+ cells. Significant correlations between percentage of lymphocytes in the subsequent stages of apoptosis (early, late and necrosis) were found in a subgroup III of cleanup workers exposed to doses higher than 500 $\mathrm{mSv}$ (Annexin+PI- \% vs Dose: $\mathrm{r}=-0.17$; Annexin $+\mathrm{PI}+\%$ vs Dose: $\mathrm{r}=-0.12$; Annexin-PI $+\%$ vs Dose: $r=-0.32 ; p<0.05)$.

Our study revealed differences in cell entry to apoptosis at the late period after exposure due to radiation dose. Changes in proportion of cells susceptible to apoptosis and cells expressing the anti-apoptotic proteins in doses below $500 \mathrm{mSv}$ show dependencies with dose and are accompanied with the entry of cells into apoptosis. At high doses increased FAS + fraction and number of AnnexinV+PI- cells together with a decrease percentage of cells expressing bcl-2 antiapoptotic protein weren't associated with increase of cells at later stages indicating the incompleteness of apoptosis. These data are confirmed by research at the molecular level.

Investigation of expression of gene regulating FASpathway of apoptosis - FASL, showed overexpression

\section{Table 1}

Percentage of lymphocytes expressing CD95 receptor and anti-apoptotic Bcl2 protein in the groups of cleanup workers divided by radiation dose

\begin{tabular}{|c|c|c|c|c|}
\hline \multirow{3}{*}{ Indexes (\%) } & \multicolumn{4}{|c|}{ Groups } \\
\hline & \multirow[b]{2}{*}{ Control } & \multicolumn{3}{|c|}{ Chornobyl clean-up workers } \\
\hline & & $\begin{array}{l}\text { I subgroup } \\
(0<D \leq 100)\end{array}$ & $\begin{array}{c}\text { II subgroup } \\
(100<D \leq 500)\end{array}$ & $\begin{array}{l}\text { III subgroup } \\
(D>500)\end{array}$ \\
\hline $\mathrm{CD} 95+(\mathrm{M}+\mathrm{SD})$ & $19.26 \pm 9.32$ & $29.18 \pm 9.85$ & $32.56 \pm 9.81$ & $35.20 \pm 9.68$ \\
\hline $\mathrm{t}$-value & - & -6.41 & -9.07 & -8.51 \\
\hline $\mathrm{p}$ & - & $<0,0001^{\star}$ & $<0.0001^{\star}$ & $<0.0001^{\star}$ \\
\hline $\mathrm{n}$ & 68 & 91 & 119 & 41 \\
\hline $\mathrm{Bcl} 2+(\mathrm{M}+\mathrm{SD})$ & $37.84 \pm 8.21$ & $32.31 \pm 6.09$ & $33.65 \pm 8.01$ & $32.66 \pm 12.31$ \\
\hline t-value & - & 3.76 & 2.83 & 2.58 \\
\hline $\mathrm{p}$ & - & $<0.05^{\star}$ & $<0.03^{*}$ & $<0.01^{\star}$ \\
\hline $\mathrm{n}$ & 68 & 42 & 54 & 37 \\
\hline
\end{tabular}






of this gene in leukocytes of PB of clean-up workers exposed in the dose range more than $500 \mathrm{mSv}$, showing the same type of changes at this level of apoptosis on the transcriptional and translational levels (Figure 1, A). However, a significant increase of FASL gene expression not accompanied, at group level, increased number of AnnexinV+PI- cells in the early stages of apoptosis (Figure 1B, 1C), confirming incompleteness of programmed cell death in this dose range. The explanation is the depletion of apoptotic response in a remote period after exposure to high doses, and it could enhance the aging process, accumulation of mutations and malignant transformation. Evidence on the existing of such violations in a remote period after radiation exposure in the dose range of more than $500 \mathrm{mSv}$ could be confirmed by the overexpression of the BIRC5 (encoding survivin protein) gene inhibiting apoptosis associated with the decrease in expression of pro-apoptotic $B A X$ and $M A D D$ genes (Figure 2A, 2B, 2C). BIRC5 overexpression in a subgroup of cleanup workers exposed to doses more than $500 \mathrm{mSv}$ could be an unfavorable sign of absence of elimination of transformed cells and explains a number of apoptosis block effects in this dose range. MADD protein mediates activation of mitogen-activated protein kinase (MAPK), which is part of a kinase cascade, which is partially regulated by gene MKNK2. MKNK2 gene expression was characterized by a downward trend in all study groups, but statistically significant differences to unexposed control indices were registered only in a subgroup of exposed below $100 \mathrm{mSv}$.

Genome changes resulting from influence of lowLET radiation, can modify the fundamental cell-tissue processes, including the acceleration of cell aging (regulation of telomere length, arrest the cell cycle), apoptosis and/or compensatory proliferation, violation of signal transduction and cell transformation [8]. Indisputably important is the way of implementing genetic changes. The cellular senescence, apoptosis and blast transformation represent keen and interrelated reactions of cells in the presence of stress factors [9]. Violation in synergy between the basic homeostatic systems amongst the gradual depletion of adaptation reserves promotes sustainable systemic changes in the immune system due to ionizing radiation. The violation of apoptosis gene regulation could be influenced by endogenous and exogenous factors, including ionizing radiation [10]. Gene regulation of apoptosis is a process of delicately tuned balance of pro- and anti-apoptotic mechanisms, and transit to 


\section{КЛІНІЧНI}

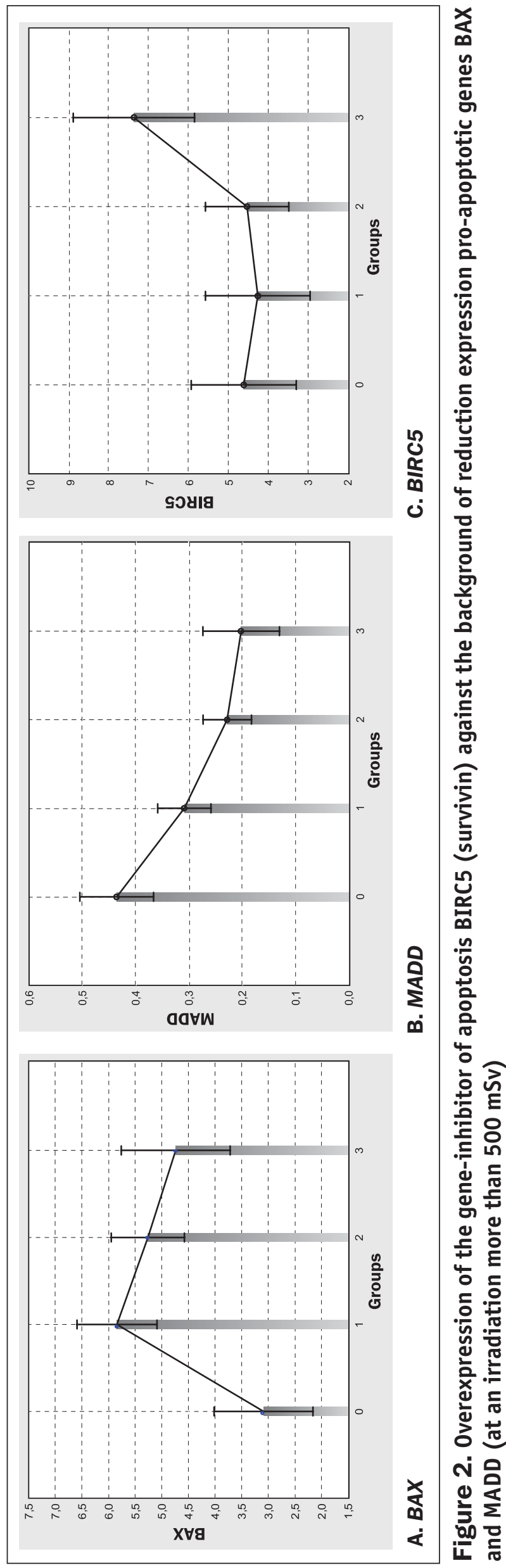

its late stages is regulated by a set of clearly defined genes. The keen role among them is played by TP53, which is responsible for the regulation of the cell cycle and in not mutated state acts as a suppressor of malignant transformation [11]. It is shown that enhancers and inhibitors of apoptosis or directly affecting cell death mechanisms, or indirectly - by influencing the regulation of transcription. The role of radiation-induced alternative transcription and splicing could be also applicable in biological dosimetry [13].

DNA damage activates check points, leading to a delay in proliferation or initiation of a programmed cell death to remove potentially harmful mutations. Due to a type of repair error-prone cell fraction could increase and the progeny became genetically unstable and could undergo transformation. A key role in the cell cycle G1- check point is played by p53, which acts as a mediator of proteins signal that recognize DNA damage to effectors that stop the cell cycle [15]. In our study it was shown statistically significant increase of TP53 gene expression in remote period after exposure only in the dose subgroup of cleanup workers in the dose range of $\mathrm{D}>500 \mathrm{mSv}$ (Figure 3A). TP53 gene activation is associated with the launch of programmed cell death, which was confirmed in our study. Subgroup of cleanup workers exposed in a dose range from 100 to $500 \mathrm{mSv}$ is characterized by a correlation between the percentage of CD95+ cells and TP53 gene expression $(r=0.27)$, whereas the subgroup of cleanup workers exposed to doses more than $500 \mathrm{mSv}$ is characterized by a higher degree of interaction $(r=0,89(p<0.05))$ between the expression of FAS-receptor and RQ of TP53. Also, a correlation is revealed between the level of intracellular expression of anti-apoptotic Bcl2 protein and RQ of TP53 gene in group of Chornobyl cleanup workers (subgroup I: $r=-0,48$, subgroup II $\mathrm{r}=-0.34$, III subgroup $-\mathrm{r}=0.66)(\mathrm{p}<0.05)$. Different strength of correlation was demonstrated between the relative levels of TP53 gene expression and intracellular levels of its product - the protein p53 in dose subgroups: with Pearson coefficients in I subgroup of: $\mathrm{r}=0.36(\mathrm{p}<0.05)$, II subgroup $-\mathrm{r}=$ $0.96(\mathrm{p}<0.05)$, the third subgroup $-\mathrm{r}=0.68(\mathrm{p}<$ $0.05)$. These data demonstrate the positive effects of translational regulation of TP53. The character of changes the RQ of TP53I3 gene similar in TP53 gene expression (Figure 3, B). 


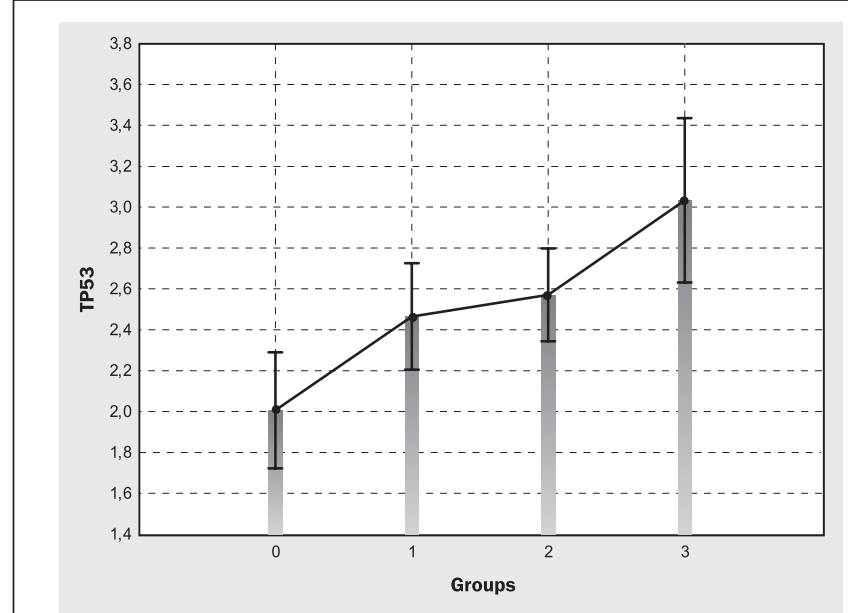

A. TP53

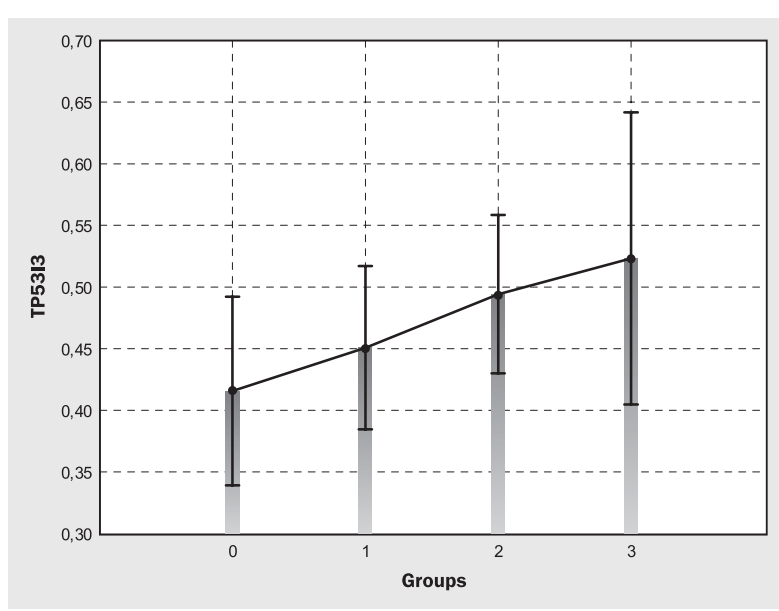

B. TP53I3

Figure 3. Dose-dependent increase in of TP53, TP53 I3 gene expression in a remote period after exposure

Analysis of TERF1, TERF2, TERT gene regulation relative telomere length in peripheral blood lymphocytes of Chornobyl clean-up workers 1986-1987, depending on age and radiation dose

Radiation induced cell aging is one of the most controversial biological effects. To characterize the cellular aging process and evaluate contribution of radiation dose the relative telomere length (RTL) was studied. A decrease in RTL values was shown in exposed groups compared to the control (Table 2). Marked RTL reduction was registered in the group of Chornobyl cleanup workers exposed to doses below $100 \mathrm{mSv}$.

The length of telomeres in somatic cells is influenced not only by various exogenous and endogenous pathogenic factors, especially with age. To reveal factor of age the total group was divided by 10 -years intervals: $1-40-50,2-50-60,3-60-70$, and $4-70-80$ years old. The average numbers demonstrate a reduction in RTL from younger to elder groups (Figure 4). By a correlation analysis between the RTL and age a weak relationship was shown $(\mathrm{r}=-0.18(\mathrm{p}<0.05))$. This data is consistent with literature.
To reveal the modifying influence of age and radiation on the relative telomere length a relationship was studied between RTL and dose in subgroups. Lowpower correlations were shown under $500 \mathrm{mSv}$ $(0-100 \mathrm{mSv}-\mathrm{r}=0.18 ; 100-500 \mathrm{mSv}-\mathrm{r}=-0.11)$. At a remote period after low-dose irradiation $(<100$ $\mathrm{mSv}$ ) differences were demonstrated between radiation dose and RTL with positive correlations after low-dose exposure $(<100 \mathrm{mSv})$, changing for negative correlation in groups of exposed over 100 and 500 mSv. We've analyzed a character of RTL changes with a combination of different age and dose intervals. It was found that the most pronounced negative correlation was present in the cleanup workers group in the age range from 40 to 50 years and dose range from 100 to $1000 \mathrm{mSv}$.

A key role in the regulation of telomere length and chromosome endings play defense protein components nucleoside protein complex that are associated with double-stranded DNA. Mutations of telomere binding proteins lead to a chromosomal instability syndrome and premature aging of cells. Genes TERF1 and TERF2 and proteins encoded by them

\section{Table 2}

The relative telomere length in peripheral blood leukocytes clean-up workers exposed to a wide range of doses

\begin{tabular}{|c|c|c|c|c|}
\hline \multirow{3}{*}{ Indexes (\%) } & \multicolumn{4}{|c|}{ Groups } \\
\hline & \multirow[b]{2}{*}{ Control $(n=73)$} & \multicolumn{3}{|c|}{ Chornobyl clean-up workers } \\
\hline & & $\begin{array}{c}\text { I subgroup } \\
(0<D \leq 100) \\
(n=102)\end{array}$ & $\begin{array}{c}\text { Il subgroup } \\
(100<D \leq 500) \\
(n=123)\end{array}$ & $\begin{array}{c}\text { III subgroup } \\
(D>500) \\
(n=43)\end{array}$ \\
\hline RTL & $18.42 \pm 3.41$ & $15.68 \pm 3.31$ & $16.40 \pm 3.64$ & $16.53 \pm 3.88$ \\
\hline t-value & - & 5.31 & 3.83 & 2.73 \\
\hline $\mathrm{p}$ & - & $<0.001^{\star}$ & $<0.001^{\star}$ & $<0.007^{\star}$ \\
\hline $\mathrm{n}$ & 68 & 42 & 54 & 37 \\
\hline
\end{tabular}




\section{КЛІНІЧНІ}



A.

Figure 4. Characteristics relative telomere length in peripheral blood leukocytes of clean-up workers of total cohort depending on age (A). Correlation RTL vs Age (B).

are the main negative regulator of telomere length and an imbalance in their functioning is associated with the development of malignant transformation. In the late period after exposure a general tendency of reducing the RQ of TERF1 was demonstrated in a wide range of doses. A statistically significant decrease in TERF1 gene expression was found in II and III subgroups of clean-up workers compared with controls. A similar pattern was recorded in the study of other gene negative regulator of telomere length $-T E R F 2$. In the late period after exposure is set statistically significant downregulation of TERF2 gene expression in all subgroups of liquidators. However, the lowest average TERF2 gene expression found in the group of persons exposed in the doses over $500 \mathrm{mSv}$ (Figure 5).

TERT gene encodes a protein - telomerase reverse transcriptase, which is functioning normally leads to the preservation of telomere length at a constant level, thus compensating for end underreplication and allowing the cells divide indefinitely. Somatic cells lack telomerase activity is normal, because after a certain number of the cell cycle, the division process is broken and is running apoptosis. Activation of telomerase in somatic cells makes possible a pathological unlimited division, which along with violations of protooncogene p53, Ras, Myc and others is a crucial factor for malignant transformation of cells. On the other hand, the main criterion for the efficiency of telomerase is a number of telomeric repeats. Reducing the length of telomeres is a sign of many diseases and can be a primary consequence of telomerase dysfunction and resulting premature loss of telomeres induced by other factors [16]. The study of the TERT gene expression



B.

showed a statistically significant $(\mathrm{p}<0.001)$ increase in group average RQ in the remote period after radiation exposure in the dose over $500 \mathrm{mSv}$ (Figure 5). The study of the correlation relationships between RQ of TERT and dose of exposure confirmed a character change: In subgroup III a medium strength positive correlation $(\mathrm{r}=0.39, \mathrm{p}<0.05)$ was shown. Effects on TERT were accompanied by violation of the regulation of telomere length through telomerase gene inhibitors TERF1 and TERF2.

We analyzed the dependence between expression of telomere-telomerase complex genes and TP53 gene expression. A positive correlation between the relative levels of TERF1, TERF2 genes expression and TP53 was found at doses below $500 \mathrm{mSv}$ (I subgroup $-\mathrm{r}=$ $0.33, r=0.39$; II subgroup $r=0.70, r=0.53$, respectively) $(\mathrm{p}<0.05)$, while in a group of exposed over 500 $\mathrm{mSv}$ a correlation was detected between RQs of TERT and TP53 $(\mathrm{r}=0.44, \mathrm{p}<0.05)$.

\section{CONCLUSION}

Our study has demonstrated presence of subsequent changes in gene expression, regulatory proteins presentation, telomere length and distribution of cells by the stages of apoptosis in a late period after radiation exposure from low-dose range to doses over $500 \mathrm{mSv}$. Deregulation of apoptosis of immune cells include: increased TP53, TP53I3, FASL gene expression (positive regulation of apoptosis); imbalance in expression of pro- and anti-apoptotic genes (BAX, BIRC5); imbalance in expression of receptors that regulate the ability of cells to apoptosis (overexpression of FASreceptor with a decreased number of bcl2 protein bearing cells). The result is an incomplete process of 


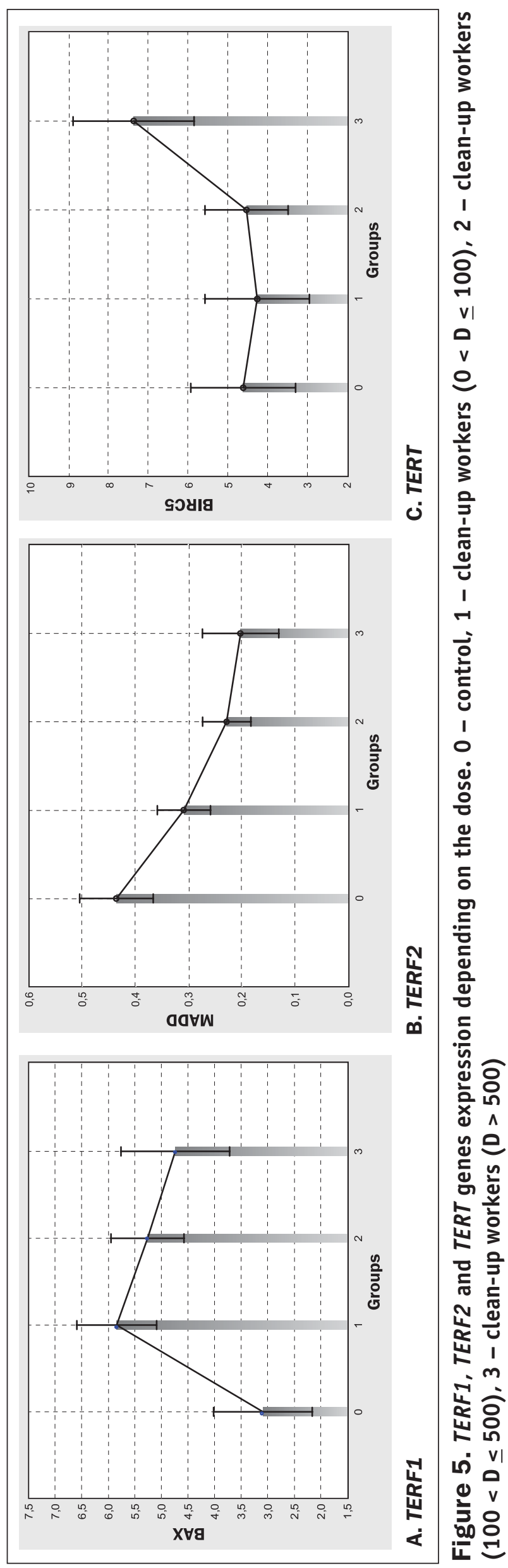

apoptosis, reduction of the number of cells as the early and late stages, manifested in the reduction of phosphatidylserine expression and the number of necrotic cells. To greatest extent these changes are determined after exposure to doses above $500 \mathrm{mSv}$.

Deregulation of cellular aging in the immune system includes: a reduction in telomere length depending on the age and fact of exposure in comparison to unexposed controls; $\mathrm{p} 53$-mediated overexpression of TERT gene in a late period after exposure to doses over 500 $\mathrm{mSv}$; together with imbalance of TERF1, TERF2 genes expression, which encode nucleoprotein complex of telomeres. The result could be cellular aging and risk of transformation.

\section{REFERENCES}

1. Bebeshko VG, Kovalenko AN, Belyi DA. [Acute radiation syndrome and its consequences]. Ternopol: TGMU; «Ukrmedkhyha»; 2006. $434 \mathrm{C}$. Russian.

2. Ryabchenko NN, Domina EA. Radiation-induced instability of human genome. Probl Radiac Med Radiobiol. 2014;19:48-58.

3. Pilinskaia MA, Shemetun AM, Dybskyi SS. [The results of 14 years of cytogenetic monitoring of priority observation contingent personnel affected by the actions of the NPP Chernobyl accident factors]. Vestnik Rossiiskoi Akademii Meditsynskikh Nauk. 2001;10:80-4. Russian.

4. Meadows SK, Dressman HK, Muramoto GG, Himburg H, Salter A, Wei Z, et al. Gene expression signatures of radiation response are specific, durable and accurate in mice and humans. PLoS One. 2008;3:e1912.

5. Riecke A, Rufa CG, Cordes M. Gene expression comparisons performed for biodosimetry purposes on in vitro peripheral blood cellular subsets and irradiated individuals. Radiat Res. 2012;178:234-43.

6. Pellegata NS, Quintanilla-Martinez L, Siggelkow H, Samson E, Bink $\mathrm{K}$, Hofler $\mathrm{H}$, et al. Germ-line mutations in p27Kip1 cause a multiple endocrine neoplasia syndrome in rats and humans. Proc Natl Acad Sci USA. 2006;103(42):15558-63.

7. Abend M, Azizova T, Muller K, Dorr H, Doucha-Senf S, Kreppel H, et al. Association of radiation-induced genes with noncancer chronic diseases in Mayak workers occupationally exposed to prolonged radiation. Radiat Res. 2015;183(3):249-61. doi: 10.1667/RR13758.1.

8. He M, Zhao M, Shen B, Prise KM, Shao C. Radiation-induced intercellular signaling mediated by cytochrome $\mathrm{c}$ via $\mathrm{p} 53$ depended pathway hepatoma cells. Oncogene. 2011;30:1947-55.

9. Short S, Woodcock M, Marples B, Joiner MC. Effects of cell cycle phase on low-dose hyper-radiosensitivity. Intern. $\mathrm{J}$ Radiat Biol. 2003;79(2):99-105.

10. Staudacher AH, Blyth BJ, Lawrence MD, Ormsby RJ, Bezak E, Sykes PJ. If bystander effects for apoptosis occur in spleen after lowdose irradiation in vivo then the magnitude of the effect falls within the range of normal homeostatic apoptosis. Radiat Res. 2010;174(6): 727-31. 


\section{КЛІНІЧНI}

11. Okazaki R, Ootsuyama A, Norimura T. TP53 and TP53-related genes associated with protection from apoptosis in the radioadaptive response. Radiat Res. 2007;167(1):51-7.

12. O'Brien MA, Kirby R. Apoptosis: a review of pro-apoptotic and antiapoptotic pathways and dysregulation in disease. J Vet Emerg Crit Care. 2008;18(6):572-85.

13. Macaeva E, Saeys Y, Tabury K, Janssen A, Michaux A, Benotmane MA, De Vos WH, Baatout S, Quintens R. Radiation-induced alternative transcription and splicing events and their applicability to practical biodosimetry. Sci Rep. 2016 Jan 14;6:19251. doi: 10.1038/srep19251
14. Ilyenko I, Lyaskivska O, Bazyka D. Analysis of relative telomere length and apoptosis in humans exposed to ionising radiation. Exp Oncol. 2011;33(4):235-8.

15. Herbig U, Sedivy JM. Regulation of growth arrest in senescence: telomere damage is not the end of the story. Mech. Ageing Develop. 2006;127:16-24.

16. Zvereva ME, Shcherbakova DM, Dontsiva OA. [Telomerase: Structure, function and regulation of the activity path]. Advances of Biological Chemistry. 2010;50:155-202. Russian.

Received: 05.07.2016 